\title{
Recent Trends in Tropical Cyclones Over the Arabian Sea and the Vulnerability of India's West Coast
}

Stefy Thomas ( $\nabla$ stefythomas@cusat.ac.in )

Cochin University of Science and Technology https://orcid.org/0000-0001-6890-8515

Lekshmy P.R.

Cochin University of Science and Technology

\section{Research Article}

Keywords: Tropical Cyclone, Accumulated Cyclone Energy, Power Dissipative Index, Vulnerable Districts, Arabian Sea

Posted Date: January 31st, 2022

DOI: https://doi.org/10.21203/rs.3.rs-1161699/v1

License: (c) (i) This work is licensed under a Creative Commons Attribution 4.0 International License.

Read Full License 

Sea and the Vulnerability of India's West Coast

7

Received: date / Accepted: date

\begin{abstract}
The IPCC's sixth assessment report emphasizes the increase in the frequency of stronger Tropical Cyclones (TC, category 3-5) over the last four decades. The Northern Indian Ocean (NIO) exhibits identical trends. The Arabian Sea (AS) has become a breeding ground for TCs that have wreaked havoc on Oman, UAE, Iran, Muscat, and India's west coast in recent years. The west coast of India is extremely vulnerable to TCs due to its unique coastal topography and population density. Most of the research on the North Indian Ocean is focused on Bay of Bengal (BoB) TCs, which necessitates rigorous studies in AS. The focus of this study is to improve our understanding of TC activity over AS by analysing the frequency of TCs and explaining observed higher intensity TCs in terms of Accumulated Cyclone Energy (ACE) and Power Dissipative Index (PDI) over the last 39 years. Energy metric analysis confirms the increasing intensity of TCs in AS. Annual ACE and PDI have been increasing in recent years primarily due to monsoon and post-monsoon TCs. While pre-monsoon TCs show a decreasing trend. The effect of El-Nino Southern Oscillation (ENSO) on TCs in AS is found to be negligible. The study also attempts to ascertain the vulnerability of western coastal districts to TCs using housing damage risk data Vulnerability Atlas of India. Ahmedabad and Vadodara in Gujarat, Thane and Mumbai Suburban in Maharashtra, Dakshin Kannada in Karnataka, and Malappuram, Ernakulam, and Thiruvananthapuram in Kerala are among the most vulnerable districts along India's western coast.
\end{abstract}

Keywords Tropical Cyclone · Accumulated Cyclone Energy · Power Dissipative Index $\cdot$ Vulnerable Districts $\cdot$ Arabian Sea

Stefy Thomas

Department of Atmospheric Sciences, Cochin University of Science and Technology, Cochin, 682016, Kerala, India

E-mail: stefythomas@cusat.ac.in

Lekshmy P. R.

Department of Atmospheric Sciences, Cochin University of Science and Technology, Cochin, 682016 ,

Kerala, 


\section{Introduction}

Tropical cyclones (TCs) are one of the most frequently occurring hydrometeorological disasters in tropical and subtropical latitudes, wreaking havoc on sea-based regions and the coast (Wahiduzzaman and Yeasmin 2019). Numerous dangers accompany TCs, including wind (Zhou et al. 2018), storm surges (Kohno et al. 2018), and widespread rainfall events (Knutson et al. 2019). TCs are the most destructive natural disasters on the North Indian Ocean's rim, claiming thousands of lives and causing billions of dollars' worth of property damage (Alam and Collins 2010; Girishkumar and Ravichandran 2012). Around $40 \%$ of the world's population lives within 100 kilometers of the coast (Barua et al. 2021) making the coastal region extremely vulnerable to TC events. India's coastline is approximately 7516 kilometres long and forms part of the coastal zone along with NIO (encompassing the Arabian Sea (AS) and the Bay of Bengal (BoB)). NIO accounts for $7 \%$ of global TC activity (Singh et al. 2001). Due to India's narrow continental shelf, flat coastal topography, high population density, geographical location, and physiological characteristics, it is extremely vulnerable to cyclones and related dangers (NDMA 2017; Kumar 2020).

In developing countries such as India, the coastline population is growing primarily due to urbanization of rural areas. In a climate change scenario, TCs and their associated storm surges pose significant challenges particularly affecting the coastal community (Rao et al. 2020). According to recent IPCC reports, the proportion of stronger TCs (Category $3-5$ ) has increased over the last four decades, and the average maximum wind speed of a tropical storm in the Atlantic and Pacific Oceans will increase by $2-11 \%$ over the next century (IPCC 2021, 2013). Numerous studies have revealed a global increase in the frequency and strength of TCs. The North Atlantic Ocean is observed to have the greatest increase in TC frequency and intensity among the ocean basins (Deo et al. 2011; Elsner et al. 2008; Webster et al. 2005; Walsh et al. 2016). Other basins, such as the north and south Indian oceans, and the south-western Pacific oceans, have also seen an increase in the frequency of TCs (Deo et al. 2011). Recent research on TCs in the NIO corroborates the IPCC's findings. Deo and Ganer (2014) finds that the intensity of tropical cyclones in the NIO has increased over the last 15 years. Sahoo and Bhaskaran (2016) determined that the accumulation of cyclone energy in the BoB has increased significantly since 1980. Singh et al. (2000) reports an increase in the prevalence of TCs in BoB, but not in AS. Balaguru et al. (2014) finds that the intensity of post-monsoon TCs in BoB has increased in conjunction with rising sea surface temperature and upper ocean heat content. Many more studies have shown an increase in TCs in NIO (Balaji et al. 2018; Deshpande et al. 2021; Bhardwaj et al. 2019; Sattar and Cheung 2019). Singh et al (2020) had discovered the unusual tracks of TCs over AS and rapid intensification is a result of warm ocean. 
The majority of NIO research is focused on BoB TCs, which are known for their cyclone activity and damage to the Indian coast. In comparison to $\mathrm{AS}$, TCs are approximately four to five times more abundant in BoB (Bhardwaj et al. 2019) approximately 10\%-20\% with a mean frequency of 1.33TCs each year (Soltanpour et al. 2021). Following the history of AS TCs, the first cyclone to make landfall on the Somalia coast was a very severe cyclonic storm (VSCS) in AS in 1994. Though the possibility of a cyclone making landfall over the AS coast is scarce, several strong TCs have recently approached these coastlines, including Gonu (2007), Nilofar (2014), Chapla (2015), Megh (2015), Mekunu (2018), Maha (2019) and Kyarr (2019). In 2007, super cyclone (SuCS) Gonu made two landfalls after passing through the Gulf of Oman, the first near Muscat and the second on Iran's southern coasts. Gonu caused over USD 4 billion in damage and killed 78 people (IMD 2008), whereas cyclones Phet and Megh (IMD 2016) killed 47 and 18 people, respectively (Bandyopadhyay et al. 2011). A few TCs had a significant impact on the low-lying coastlines of Oman, the United Arab Emirates (UAE), and Iran's (Vieira et al. 2021). SuCS Kyarr (2019) dumped 25mm of rain over Maharashtra, wreaking havoc on the agriculture sector (IMD 2021). The track of all TCs detected in AS during the study period is depicted in supplemental figures (Fig S1). Researchers (e.g., Deshpande et al. 2010; Mukhopadhyay et al. 2011; and Osuri et al. 2012) have built atmospheric models to aid in forecasting TCs over the AS. Some publications have recently identified an increase in the intensity of TCs in the AS basin during the last few decades. Murakami et al. (2013) predicted a significant increase in TC frequency over AS based on simulations using the Japan global model. According to Murakami et al. (2017), anthropogenic forcing accelerated the growth of extremely severe cyclonic storms (ESCS) over AS. Studies on AS (Evan and Camargo 2011; Murakami et al. 2017; Chowdhury et al. 2020) indicate that TCs have become more intense and frequent in recent years, implying that AS should be given increased attention due to its potential to affect many countries along the coast. Regardless of the magnitude of the AS TCs' impact, the basin has received significantly less attention than the BoB basin. While AS TCs are investigated in conjunction with BoB as a component of NIO TCs, only a few studies have examined AS as a source of TCs on its own (Zhang and Villarini 2019).

The present study examines trends in the frequency of TCs across the AS from 1982 to 2020 and attempts to gain a better understanding of the distribution and trends of the intensity of TCs (Accumulated Cyclone Energy, ACE and Power Dissipative Index, PDI). We further classified districts on India's west coast according to their housing vulnerabilities to TCs.

This paper is divided into five sections. Following the introduction in Sect.1, Sect.2 describes the data sources and methodologies used to analyze the cyclone parameters and classify cyclone vulnerable areas. The analysis result and trends in TCs over AS is described in Sect.3 and discussed in line with the existing literature in Sect.4. Sect. 5 summarizes the study findings. 
182

183

184

185

186

187

188

189

190

191

192

193

194

\section{Data and Methodology}

The AS TCs are examined in this study over 39 years from 1982-2020. This is a significant and stable period, as it is the post geostationary satellite era (Deshpande et al. 2021). The frequencies of tropical cyclones are derived from the Indian Meteorological Department's Cyclone e-Atlas (IMD). The storm's intensity (maximum sustained wind speed) and details about the cyclone's origin and landfall are derived from IMD's best-track data for cyclonic storms (version 2.0/2011 version) (https://rsmcnew delhi.imd.gov.in). As this study is concerned with the disaster potential of TCs, systems with a maximum sustained wind speed of less than 34 knots are excluded (Bhardwaj et al. 2019). The categories used in this study are based on those used by the IMD (Singh et al. 2016). To calculate the roof type vulnerability and wall type vulnerability, housing risk data is collected from the Vulnerability Atlas of India (BMTPC 2019).

\subsection{Accumulated Cyclone Energy and Power Dissipative Index}

ACE, introduced by Bell et al. (2000) is a measure of TC energy and is considered as a measure of storm kinetic energy. It accounts for the combined duration and strength of the TC. It is defined as the sum of the squares of the 6hourly maximum sustained wind speed (knots) of the storm. In the present study, it is calculated by adding up squares of the six-hourly maximum sustained surface wind speed (knot) and dividing by $10^{4}$ to make it an index for easier interpretation (Camargo and Sobel 2005).

$$
A C E=\sum V_{\max }^{2}\left(10^{4} k t^{2}\right)
$$

where $\mathrm{V}_{\max }$ is maximum sustained wind squared at all 6-hourly periods obtained from IMD best track data.

To characterize the destructive potential of TCs PDI (Emanuel 2005) is used in this study and is calculated as,

$$
P D I=\sum V_{\max }^{3}\left(10^{6} k t^{3}\right)
$$

This index is analogous to ACE and is approximately proportional to the budgetary damage generated by TC. Both energy metrics consider the collective effect of frequency, intensity, and duration of all the TCs for a particular year. ACE $\left(10^{4} k t^{2}\right)$ accounts for both the strength and duration while PDI $\left(10^{6} k t^{3}\right)$ underlines more on TC intensity. 
195

196

197

198

199

200

201

202

203

204

205

206

207

208

209

210

211

212

213

214

215

216

217

218

219

220

221

222

223

224

225

226

227

228

229

230

231

232

233

234

235

236

237

238

239

240

241

242

243

244

245

246

247
2.2 Mann-Kendall test and Sen's Slope Estimator

The non-parametric Mann-Kendall test (Mann 1945; Hoeffding 1957) is employed to detect a monotonic upward or downward trend in the time series of AS cyclone frequency. The detail of the analysis is given in supplementary information. The value of $\mathrm{Z}$ (normalized MK statistics) determines an upward or downward trend. If $Z$ yields a positive value, then there is an increasing trend in the time series and if $Z$ yields a negative value, which means there is a downward trend. Sen's slope estimator reveals the steepness of the trend.

2.3 Calculation of the vulnerability of a location

Indian Ministry of Housing and Urban Affairs' Building Materials and Technology Promotion Council (BMTPC 2019) published the third edition of the Vulnerability Atlas of India, which includes a Cyclone Occurrence Map of Coastal India based on maximum/estimated 3-minute average maximum sustained wind. Additionally, the atlas illustrates the housing risk associated with various locations based on the wall and roof types.

Housing damage risk tables were created by BMTPC (2019) by linking dwelling types, hazard intensities on the map, and damage risk levels. The districts susceptible to AS TCs in the coastal states of Kerala, Karnataka, Goa, Maharashtra, Gujarat, Daman \& Diu, and Lakshadweep are classified based on the style of the house. Two types of vulnerabilities occur depending on the type of house: 1) Roof type vulnerability and 2) Wall type vulnerability. Districts from western coastal states that fall into the four proneness categories (as per RSMC reports) were chosen for categorization. RSMC calculates the proneness based on the frequency of total cyclones, total severe cyclones, actual/estimated maximum wind speeds, probable maximum storm surge associated with cyclones, and probable maximum precipitation.

The vulnerability atlas is used to identify the number of houses with lightweight sloping roofs (L), heavyweight sloping roofs $(\mathrm{H})$, and flat roofs (F), and a weighted average is calculated for each district to calculate roof type vulnerability (RTV). Because the level of resistance varies for different types of walls under different wind conditions, the study assigns different weights to each wall type when evaluating RTV. A level roof is given a 0.5 weight, a lightweight sloping roof is given a 1.5 weight, and a heavyweight sloping roof is given a weight of 1 .

$$
\text { Roof type vulnerbility }(R T V)=\frac{((R 1 \times L \times 1.5)+(R 2 \times H \times 1)+(R 3 \times F \times 0.5))}{(R 1+R 2+R 3)}
$$

where, R1, R2 and $\mathrm{R} 3$ are the percentages of houses with $\mathrm{L}, \mathrm{H}$ and $\mathrm{F}$ roof types respectively. L, $\mathrm{H}$ and $\mathrm{F}$ here denote the number of houses with respective roof types. The RTV for each district is calculated and divided by, $10^{5}$ to construct an index for easy comprehension. According to the RTV values, the districts are classified as high risk, medium risk, or low risk. 
To calculate wall type vulnerability, the number of houses with mud and unburnt brick walls (A1), wood walls (C2) and other materials (X) are identified from the data (BMTPC 2019). The weighted average of this data gives wall type vulnerability of a district.

Wall type vulnerability $(W T V)=\frac{((W 1 \times A 1)+(W 2 \times C 2)+(W 3 \times X))}{(W 1+W 2+W 3)}$

where, W 1, W 2 and $\mathrm{W} 3$ are the percentage of houses with A1, C2 and X wall types respectively. A1, $\mathrm{C} 2$ and $\mathrm{X}$ here denote the number of houses with respective wall types. To produce an index for easier comprehension, the WTV for each district is calculated and divided by, $10^{4}$. According to the WTV values, the districts are classified as high risk, medium risk, or low risk. Table 1 shows the risk levels for RTV and WTV.

\section{Results and Discussion}

\subsection{Frequency of TCs (1982-2020)}

The frequency of all TCs from 1982-2020 are depicted in figure 1 for five distinct storm types: CS, SCS, VSCS, ESCS, and SuCS. 45 TCs formed in AS during the period. AS is found to be active in most years with at least one TC and up to five TCs per year while it did not experience TCs in years 1983, 1984, 1986-1991, 1997, 2000, 2005, 2008, 2013, 2016, and 2017. BoB is known to have the highest concentration of TCs in the NIO basins. However, there have been some recent years in which AS TCs outnumbered BoB TCs (2001, 2004, 2014, 2015, and 2019) as well as years in which both AS and BoB TCs had an equal share of NIO TCs (1993, 1994, 1998, 2007, 2011 and 2012). During this period $17(38 \%)$ of the 45 TCs that formed are CS, 10(22\%) are SCS, $7(16 \%)$ are VSCS, $9(20 \%)$ are ESCS, and 2(4\%) are SuCS.

The trend line in figure 1 shows that the number of TCs in AS has been increasing over time. To ascertain the recent trend in TC frequency, we divide the 39-year period into two segments: the bygone era (BE), 1982-2000 and the modern era (ME), 2001-2020. Figure 2a illustrates the frequency of TCs in BE and ME. ME has 31 total TCs, compared to 14 in BE, a $54.8 \%$ increase. It is concerning to note that ME had two SuCS, whilst BE had none. From BE to ME, VSCS indicates a maximum rise of $60 \%$. From BE to ME, ESCS exhibits a $50 \%$ growth. In comparison to $\mathrm{BE}, \mathrm{ME}$ had a $58 \%$ rise in CS. SCS indicates a minimum of a $33 \%$ increase from BE to ME when compared to other categories. As observed from Fig 2a, the number of cyclones intensifying to VSCS or higher has increased. 
Figure 2b illustrates the seasonal distribution of TCs over AS. The occurrence of TCs is demonstrated to be negligible in January and February. The cyclone season in AS begins in the pre-monsoon season (March-AprilMay); May (9) has the highest occurrence of tropical cyclones during the pre-monsoon season. March and April are devoid of TC incidents. Monsoon season (June-September) is responsible for a sizable portion of the annual $\mathrm{TC}$ frequency. Cyclones occur most frequently during the monsoon season in June (10) and September (4). July and August have no TC events.

Post-monsoon season TCs contribute the most to the annual frequency of TCs during (October to December). TCs are most prevalent in October (12), followed by November (8) and December (2). Thus, the AS is most active during the post-monsoon and monsoon seasons, particularly in May, June, October, and November.

To establish the trend in the frequency of TCs over AS, the Mann-Kendall (MK) test is used. The results of the MK test to determine the frequency of cyclones over AS are reported in Table 2. The MK test validates the existence of a nonlinear increasing trend in the annual frequency of TCs in AS with a $95 \%$ confidence level. The annual frequency of TCs has a $\mathrm{Z}$ value of 2.4004 and a p-value of 0.016. The considerable annual increase in the frequency of higher category TCs is due to an increase in the frequency of $\operatorname{ECSC}(\mathrm{Z}=2.0987$ and $\mathrm{p}=0.035$ ). This conclusion is consistent with recent ESCS events such as Nilofar (2014), Chapla (2015), Megh (2015), Mekunu (2018), and Maha (2019). The MK test did not reveal any significant trends in the frequency of CS, SCS, VSCS, or SuCS because the p-values for any of these categories are more than 0.05. Thus, the MK test indicates that the annual frequency and frequency of ESCS have a substantial upward trend, whereas the other four categories exhibit no monotonic trend. 
3.2 Arabian Sea and Bay of Bengal comparison

Figure 3 shows the frequency of TCs by category in AS and BoB from 1982 to 2020. Figure $3 \mathrm{a}$ illustrates the frequency of CS. Both basins are trending down in the frequency of $\mathrm{CS}$, with BoB experiencing a greater decline. The frequency of SCS is depicted in Figure 3b; a sharp decline in the frequency of BoB SCS can be observed. AS SCS also exhibits a downward trend. Figure $3 \mathrm{c}$ illustrates VSCS, which depicts the frequency of higher intensity TCs. Surprisingly, while the frequency of VSCS appears to be decreasing for BoB, it appears to be increasing for AS. After 2010, the AS VSCS slope exhibits a more pronounced increase. In terms of ESCS frequency, AS has a significantly increasing trend, whereas BoB TCs do not (Figure 3d). SuCS frequency is shown in Figure 3e, which is stationary in both AS and BoB. Super cyclones were confined to BoB; there were no super cyclones in AS until after 2007. In the six years from 2014 to 2020, five ESCS and four VSCS occurred in AS, out of a total of nine ESCS and seven VSCS over 39 years. During this period, AS was also struck by two SuCS, transforming it into a hotspot for strong cyclonic activity. The declining trend in CS and SCS in BoB and AS suggests an increased proclivity for TCs intensification, which increases the frequency of VSCS, ESCS, and SuCS.

\subsection{TC Energy Metrics}

Table 3 shows the basic statistical values of ACE and PDI in the AS from 1982 to 2020. The ACE (PDI) value ranges from o to $51.22 \times 10^{4} \mathrm{kt}^{2}(44.56 \times$ $\left.10^{6} \mathrm{kt}^{3}\right)$. Annual mean values for the ACE and PDI are 5.05 (SD =9.85) and $3.91(\mathrm{SD}=8.50)$, respectively. Additionally, Table 3 contains data for the pre-monsoon, post-monsoon, and monsoon seasons. The post-monsoon values of ACE and PDI exhibit significant variations, with SDs of 7.25 and 6.71, respectively. Annual ACE has the least dispersion around the mean, with a coefficient of variance of 1.95 , while pre-monsoon PDI has the most dispersion, with a coefficient of mean of 3.31. This indicates that there is considerable uncertainty regarding cyclones' pre-monsoon damage potential.

The ACE and PDI time series for all TCs are shown in Figure 4. Both the $\mathrm{ACE}$ and PDI trendlines in Fig 4a demonstrate an increasing trend in the annual values of the parameters. The rising trend can be confirmed with $95 \%$ confidence, and the ACE slope is $0.368 \pm 0.13$ and that of PDI is 0.305 \pm 0.12 . This conclusion is comparable to the rising trend in the frequency of higher category TCs reported in Section 3.1. To examine variations over time, the ACE and PDI values for $\mathrm{BE}$ and $\mathrm{ME}$ are plotted. 
The values of ACE and PDI are observed to increase during ME. The ACE plots for BE and ME are shown in Figures $4 \mathrm{~b}$ and $4 \mathrm{c}$, and the PDI plot is given in the supplementary figures (Fig S2). It is determined that the maximum value of ACE (PDI) during BE is $11.29 \times 10^{4} \mathrm{kt}^{2}\left(11.11 \times 10^{6} \mathrm{kt}^{3}\right)$, whereas the maximum value of ACE (PDI) during ME is $51.22 \times$ $10^{4} \mathrm{kt}^{2}\left(44.56 \times 10^{6} \mathrm{kt}^{3}\right)$. These findings indicate that the energy of TCs has recently increased, as has their destructive potential. The slope of the premonsoon ACE (PDI) is decreasing in ME, whereas the post-monsoon ACE (PDI) exhibits a significant upward slope of $0.757 \pm 0.35(0.689 \pm 0.33)$. The annual increase in ACE (PDI) levels in AS is attributed to post-monsoon ACE (PDI) values.

The non-parametric MK test and Sen's slope estimator are used to analyze ACE and PDI trends in the data. The MK test results are summarized in Table 4. The MK trend test demonstrates a 95\% statistically significant increase in annual ACE and PDI. Annual ACE and PDI both exhibit a significant upward trend, with magnitudes of 0.0436 and 0.017 (Sen's slope estimator values), respectively. The significant increase in annual ACE (PDI) is associated with an increase in VSCS and ESCS in AS, which is evident in ACE from 2014 to 2020. Pre-monsoon and post-monsoon seasons also exhibit a rising trend, but this is not statistically significant. The MK test, on the other hand, indicates a positive trend for both ACE and PDI during the monsoon season with a $95 \%$ confidence interval.

As a result of an increase in post-monsoon and monsoon season TC activity, the energy metric of TCs in AS has been increasing over the study period. Increases in these characteristics indicate that the wind speed, duration, and severity of TCs in AS, as well as their destructive potential, have increased over the study period. Sen's slope estimator estimates for annual ACE (0.044) and PDI (0.016) suggest that the MK test's substantial positive trend is critical. Sen's slope estimator for seasonal values of ACE and PDI was zero, indicating a negligible slope in their trend lines, even though several of the parameters exhibit a significant trend in the MK test. 


\subsection{Monsoon and TCs}

The monsoon season is well-known for depressions and deep depressions. The present study finds that there are more TCs in AS during the monsoon (JJAS), particularly in June, during ME than BE. Supplementary figures (Fig S3) explain the increase in ACE and PDI values in AS during the monsoon season. The number of TCs (6), ACE (slope $=0.127 \pm 0.16$ ), and $\mathrm{PDI}$ (slope $=0.068 \pm 0.13$ ) increase more rapidly during ME than during BE. Also the MK test for seasons showed a significant positive trend in monsoon values of ACE and PDI. As discussed in sections 3.1 and 3.2, monsoon TCs contributed a significant amount to annual TC frequency, ACE, and PDI during this period, and this trend is expected to continue in the future, as illustrated in figure 5. ACE and PDI are depicted in Figures $5 \mathrm{a}$ and $5 \mathrm{c}$ in BE, respectively, while 5b and 5d depict ACE and PDI in ME. ACE and PDI values in BE have been increasing since 1998, but the increase has been gradual. ACE and PDI values, on the other hand, exhibit a steeper increasing trend with more abrupt values in ME.

\subsection{Influence of ENSO on AS TCs}

ENSO events have remote controls on the climate of many places over the globe. The present study analyzes the effect of ENSO events on AS TCs. Over the course of 39 years, the analysis identified 13 El- Nino years (1982, 1986, 1987, 1991, 1994, 1997, 2002, 2004, 2006, 2009, 2014, 2015, 2018), 13 La-Nina years (1983, 1984, 1988, 1995, 1998, 1999, 2000, 2007, 2010, 2011, 2016, 2017, 2020), and 13 neutral years (1983, 1984, 1988, 1995, 1998, 1999, 2000, 2007, 2010, 2011, 2016, 2017, 2020). During this period, 17 (38\%) of the 45 TCs were formed during El Nino years, 16 (35\%) during neutral years, and $12(27 \%)$ during La Nina years. There is no discernible pattern to these occurrences. 
431

432

433

434

435

436

437

438

439

440

441

442

443

444

445

446

447

448

449

450

451

452

453

454

455

456

457

458

459

460

461

462

463

464

465

466

467

468

The Nino 3.4 values were then correlated with the frequency of TCs, ACE, and PDI to determine if there is a correlation between Nino 3.4 sea surface temperature anomaly and AS TCs. There was no correlation between Nino 3.4 values and TC parameters that was statistically significant (at the 95\% significance level). Pearson's correlation coefficient of TC frequency (0.075), ACE (0.142), and PDI (0.131) are not statistically significant. This concludes that the ENSO events have no discernible effect on the frequency of TCs, ACE, or AS PDI. Examination of ENSO demonstrates that we cannot attribute the occurrence of active TC in AS solely to this large-scale climate variability. Additionally, the distribution of TCs is random. For example, the most active TC year in AS was 2019 with five TCs, a neutral year; 2018 was another active year in AS with three TCs, an El-Nino year; and 1998 was a La-Nina year in AS with three TCs, also a neutral year. The characteristics of SSTAs and TCs are depicted in Figure 6.

3.6 Vulnerability of districts in the west coast of India based on roof and wall types

The vulnerability of each district in the western coastal states using the RTV and WTV indices is depicted in Figure 7. The districts in the west coast that are being considered are listed in Table $\mathrm{S} 2$ of supplementary materials. The RTV and WTV indices for each district are calculated, and the districts are classified accordingly.

Gujarat: Gujarat is a large state with cyclone-prone districts. Gujarat's coastal districts are classified as P2 (highly prone) and P3 (moderately prone) hazard prone districts (Mohapatra 2015). Ahmedabad, Surat, Rajkot, and Vadodara are classified as moderately vulnerable, whereas Junagadh, Kutch, Bhavnagar, Amreli, Jamnagar, Anand, Navsari, Valsad, Bharuch, and Porbandar are classified as lowly vulnerable according to the type of roofing material used.

Ahmedabad, Bhavnagar, Anand, and Vadodara, according to WTV, are moderately vulnerable due to the type of wall. Junagadh, Kutch, Amreli, Jamnagar, Surat, Valsad, Bharuch, Porbandar, and Rajkot all have a low vulnerability level. The proportion of houses with unburned brick walls, wood walls, and other lightweight materials is greater in moderate-risk districts than in low-risk districts. Ahmedabad and Vadodara districts face a moderate risk when compared to the rest of Gujarat's coastal districts. 
Maharashtra: The RSMC classifies Maharashtra's coastal districts as P3 districts, which means they are moderately prone to cyclones. Thane and Mumbai Suburban are considered high-risk areas by the RTV index. Mumbai Suburban has a very high RTV index value (10.7). Ratnagiri is the next most vulnerable. Other coastal districts such as Sindhudurg and Raigarh exhibit low vulnerability as indicated by the RTV index. Districts are classified differently in the WTV index. According to the WTV index, Thane and Raigarh are highly vulnerable, while Mumbai suburban and Ratnagiri are moderately vulnerable, and Sindhudurg is exhibit very low vulnerability. In summary, Thane and Mumbai Suburban are Maharashtra's most vulnerable districts.

Goa: The RSMC classifies Goa as cyclone-prone in the P3 category. Apart from that, this study discovers that both North and South Goa fall into the low vulnerability category according to the RTV and WTV indices. There is only a very slight difference in index values between North and South Goa.

Karnataka: Udupi, Uttar Kannada, and Dakshin Kannada are the three coastal districts in Karnataka. On the RSMC's cyclone proneness map, all these districts are classified as $\mathrm{P}_{3}$. All three districts are classified as low vulnerability districts by the RTV. However, Dakshin Kannada is classified as having moderate vulnerability in the WTV classification, making it the most vulnerable district in Karnataka.

Kerala: Nine of Kerala's fourteen districts are coastal. This fact increases the state's vulnerability to hazards associated with cyclones. However, the RSMC classifies the districts of Kozhikode, Malappuram, Thrissur, Kannur, Kollam, Alappuzha, and Thiruvananthapuram as P3 (moderately prone). Ernakulam and Kasaragod are classified as $\mathrm{P} 4$ areas (less prone). Malappuram and Ernakulam are classified as moderately vulnerable districts by the RTV index, whereas the remaining districts are classified as less vulnerable. The WTV index classifies Thiruvananthapuram as moderately vulnerable, while the remaining districts are classified as less vulnerable.

Daman and Diu, Lakshadweep: Daman is classified as a P3 vulnerability by the RSMC, while Lakshadweep and Diu are classified as P2 vulnerabilities. These areas have a significantly lower population and housing density than India's western coast states. As a result, both the WTV and RTV indices used in this study classify the vulnerability of these union territories as low risk. 


\section{Discussion}

Our study on the TCs over a period of 39 years, from 1982 to 2020 reveals an increase in the frequency and intensity of TCs over the Arabian Sea. This study demonstrates that the frequency of TCs is increasing as they are becoming more intense as explained in section 3.1. We find that in ME the number of TCs belonging to higher categories (VSCS, ESCS and SuCS) are remarkably large. The frequency of VSCS is observed to increase by $60 \%$ during ME. It is also identified via MK test that there is a significant upward trend in the frequency of ESCS and this is evident in recent occurrences of TCs in AS from 2014 to 2020. This result is consistent with a trend toward stronger storms projected by Knutson et al. (2010), who predicted a 2-11 percent increase in storm intensity by 2100 . According to Knutson et al. (2013) and Kossin et al. (2013), the frequency of category 4-5 systems may increase by approximately $40 \%$ by 2100 . Sahoo and Bhaskaran (2018) finds that out of four to five TCs occurring in NIO one or two are very severe. Many studies (Deshpande et al. 2021; Murakami et al. 2017; Balaguru et al. 2014) reveals an abrupt shift toward intensification of TCs in the NIO, resulting in an increase in the number of VSCS storms in the NIO basins over the course of cyclone seasons especially in BoB. This study makes a similar finding in AS, indicating that AS is as significant globally as any other ocean basin.

Our study demonstrates that the frequency of VSCS and ESCS is significantly higher in AS than BoB. Some numerical model simulations, suggest that the frequency of global TCs is expected to decrease, not increase, in $21^{\text {st }}$ century (Knutson et al. 2010). Our study observes a decline in the frequency of CS and SCS but clear increase in the frequency of higher category TCs in both $\mathrm{AS}$ and BoB. We observed that ME witnessed consecutive ESCS incidents in 2015. Chowdhury et al. (2020) observed that warm ocean surface resulted in back-to-back occurrence of TCs over AS which is in line with our observation. Even though this study observes two SuCS in $\mathrm{ME}$, we cannot make any conclusions because the number of SuCS is extremely small in comparison to the number of individual TCs in cyclone seasons.

This study found a significant rise in ACE and PDI in AS during the period. The increase is more pronounced after 2010, implying that the strength and destructive potential of TCs have increased significantly over the years. This rise in ACE is coherent with the findings of Deshpande et al. (2021) who finds a significant increasing trend in the intensity, frequency, and duration of cyclonic storms over NIO. Sahoo and Bhaskaran (2016) report that PDI of TCs in BoB is sixfold that of the past decade. Surprisingly, this study observes a decline in ACE and PDI values during pre-monsoon in $\mathrm{ME}$ and a steep increase in post-monsoon values of the parameters. Monsoon values exhibit a similar trend to post-monsoon values, though they are less steep. Thus, the annual increase in ACE and PDI values are attributed to post-monsoon and monsoon values of these parameters. We also observe that during ME the TCs in monsoon shows abrupt values for ACE, PDI and the frequency. The increase is more gradual during BE. Such unprecedent occurrences amplify the risk associated with TCs and vulnerability. Muni Krishna (2009) predicted that the decreasing trend in tropical easterly jet because of warming ocean would facilitate the formation of hurricane intensity TCs in NIO during summer monsoon. Our findings corroborate this prediction. 
May, June, October, and November are the most active TC months in AS, according to our results. Evan and Camargo (2011) hypothesized that TCs in May and June in AS were associated with the early and late onset of the southwest monsoon, respectively. Studies such as Sattar and Cheung (2019), cover the pre-monsoon season from June to August, this study adheres to the traditional division of months into pre-monsoon, monsoon, and postmonsoon.

We also observe that ENSO events have negligible effect on TC frequency, ACE and PDI values in AS. Bhardwaj et al. (2019) and Girishkumar and Ravichandran (2012) and observes that in BoB Nino 3.4 sea surface temperature anomalies are negatively correlated with TC parameters. Camargo and Sobel (2005) observe a positive correlation between ENSO indices and western north Pacific basin TC parameters. We observe random TC events during various ENSO indices in AS. This could be because TCs are inexplicable in terms of a single mode of climate variability. Numerous climate variables are at work during a cyclone.

Rao et al. (2020) demonstrate that the Indian peninsula is affected by the intensification of TCs. In comparison to India's west coast, almost every state on the east coast is extremely vulnerable to cyclones (Mohapatra et al. 2012). Many studies have highlighted disaster-prone districts on India's east and west coasts (Mohapatra et al. 2012; Mohapatra 2015). RSMC has compiled a list of Indian districts that are prone to cyclones. According to RSMC, 72 districts that border the Indian coast have been divided into four proneness categories, with 33 districts and three union territories located on the west coast (Mohapatra 2015). This classification was made solely based on hazard, without regard for the vulnerability of a location. Additionally, studies examined the vulnerability of districts such as Orissa (Dube et al. 2000; Mohanty et.al 2020), Andhra Pradesh (Raghavan and Rajesh 2003), Tamil Nadu (Jeganathan and Andimuthu 2013) and West Bengal (Gayathri et al. 2015). It should be emphasized that these studies focus exclusively on India's eastern coastal states (Rao, 2020). Only Gujarat, on the west coast, is known to be particularly prone to cyclones. Our study concentrates on vulnerability of western coast of India and observe that Gujarat's Ahmedabad and Vadodara districts, Maharashtra's Thane and Mumbai Suburban districts, Karnataka's Dakshin Kannada district, and Kerala's Malappuram, Ernakulam, and Thiruvananthapuram districts are the most vulnerable districts along the country's western coast. It is worth noting that some districts classified as highly prone in the RSMC list fall into the less vulnerable category according to the RTV and WTV indices. This discrepancy arises because RSMC considered only the hazard aspect of TC events. The vulnerable districts according to our classification are densely populated and rapidly urbanizing, which contributes to a locality's increased risk during TC event. 


\section{Conclusion}

In recent years, the Arabian Sea has become a hotspot for TCs, with dire socioeconomic consequences for India's west coast. The purpose of this study is to gain a better understanding of tropical cyclone activity over AS by analyzing the frequency of TCs and explaining observed higher intensity TCs in terms of accumulated cyclone energy and power dissipative index. Our major findings are as follows:

- The frequency analysis of TCs reveals an increase in the annual frequency of TCs over AS from 1982 to 2020. Between BE and ME, VSCS increases by $60 \%$ and ESCS by 50\%. Additionally, the frequency of CS and SCS has decreased over time, indicating a shift in AS towards higher intensity TCs.

- $\quad$ Energy metric analysis confirms the increasing intensity of TCs over AS. It is discovered that the increase in post-monsoon and monsoon TCs contributes to the annual TC parameter increase. Increases in these characteristics indicate that the wind speed, duration, and severity of storms are increasing. The pre-monsoon parameters of TCs show a decreasing trend during ME, whereas the monsoon values show an increasing trend (June).

- Monsoon TCs contributed a significant amount to annual TC frequency, ACE, and PDI during this period, and this trend is expected to continue.

- The effect of ENSO events on TC activity in AS and conclude that ENSO has a negligible effect on TC activity in AS. Also, the TCs occurrence show a random distribution over El-Nino, La-Nina and neutral years.

- Analysis for vulnerable districts revealed that Gujarat's Ahmedabad and Vadodara, Maharashtra's Thane and Mumbai Suburban, Karnataka's Dakshin Kannada, and Kerala's Malappuram, Ernakulam, and Thiruvananthapuram are among the most vulnerable districts along India's western coast.

The study indicates that the strength and frequency of TCs in AS are expected to increase in the future. This scenario will exacerbate the vulnerability of countries such as India, the UAE, Oman, Iran, Muscat and even Somalia. The risk of damage to a location can be mitigated to a certain extent by using proper building materials, which minimize a house's vulnerability, thereby reducing the vulnerability of a district. The long-term goal of the study is to develop a disaster mitigation strategy for India's coastal

regions. 


\section{Abbreviations}

TC, Tropical cyclone; NIO, North Indian Ocean; AS, Arabian Sea; BoB, Bay of Bengal; ACE, accumulated cyclone energy; PDI, power dissipative index; ME, modern era; CS, cyclonic storm; SCS, severe cyclonic storm; VSCS, very severe cyclonic storm; ESCS, extremely severe cyclonic storm; SuCS, super cyclonic storm; RSMC, regional specialized meteorological centre; IMD, Indian Meteorological Department; MK Test, Mann-Kendall Test; BMTPC, Building Materials and Technology Promotion Council; RTV, roof type vulnerability; WTV, wall type vulnerability; BE, bygone era

\section{Competing interests}

The authors declare that they have no competing interests.

\section{Funding}

This research was supported by the Department of Science and Technology (India) Inspire Fellowship programme.

\section{Authors' contributions}

Stefy Thomas conceptualized, carried out data analysis and drafted the manuscript. Lekshmy P.R. supervised and mentored the study by holding regular discussions. The authors read and approved the final manuscript.

\section{Acknowledgement}

The authors wish to express their gratitude to the Department of Atmospheric Sciences, Cochin University of Science and Technology for facilitating the research.

\section{References}

Alam E, Collins AE (2010) Cyclone disaster vulnerability and response experiences in coastal Bangladesh. Disasters 34(4):931-954

Balaguru K, Taraphdar S, Leung LR, Foltz GR (2014) Increase in the intensity of post monsoon Bay of Bengal tropical cyclones. Geophys Res Lett 41(10):3594-3601

Balaji M, Chakraborty A, Mandal M (2018) Changes in tropical cyclone activity in north Indian Ocean during satellite era (1981-2014). Int J Climatol 38(6):2819-2837

Bandyopadhyay BK (ed) (2011) WMO/ESCAP panel on tropical cyclones annual review 2010

Barua Prabal, Rahman Syed, Eslamian Saeid (2021) Coastal zone and wetland ecosystem: management issues. In: Encyclopedia of the UN sustainable development goals. 1-19. https://doi.org/10.1007/978-3-31971064-8_144-1 
Bell, G. D., Halpert, M. S., Schnell, R. C., Higgins, R. W., Lawrimore, J., Kousky, V. E., Tinker, R., Thiaw, W., Chelliah, M., \& Artusa, A. (2000). Climate Assessment for 1999, Bulletin of the American Meteorological Society, 81(6): S1-S50. Retrieved Dec 11, 2021, from https://journals.ametsoc.org/view/journals/bams/81/6/1520$0477 \quad 2000 \quad 81$ s1 caf 2 o co $2 . x m l$

Bhardwaj P, Pattanaik DR, Singh O (2019) Tropical cyclone activity over Bay of Bengal in relation to El Niño-Southern Oscillation. Int $\mathrm{J}$ Climatol 39(14):5452-5469

BMTPC (2019) Vulnerability Atlas of India: Earthquake, Wind, Flood, Landslide, Thunderstorm Maps and Damage Risk to Housing, Published by Building Material \& Technology Promotion Council, Ministry of Housing and Urban Poverty Alleviation, Government of India

Camargo SJ, Sobel AH (2005) Western North Pacific tropical cyclone intensity and ENSO. J Climate 18(15):2996-3006

Deo AA, Ganer DW, Nair G (2011) Tropical cyclone activity in global warming scenario. Nat Hazards 59(2):771-786

Deo AA, Ganer DW (2014) Tropical cyclone activity over the Indian Ocean in the warmer climate. Monitoring and Prediction of Tropical Cyclones in the Indian Ocean and Climate Change. Springer, Dordrecht. https://doi.org/10.1007/978-94-007-7720-0 7

Deshpande M, Pattnaik S, Salvekar PS (2010) Impact of physical parameterization schemes on numerical simulation of super cyclone Gonu. Nat Hazards, 55(2):211-231. https://doi.org/10.1007/s11069-0109521-X

Deshpande M, Singh V K, Ganadhi M K et al. (2021) Changing status of tropical cyclones over the north Indian Ocean. Clim Dyn 57:3545-3567 https://doi.org/10.1007/s00382-021-05880-z

Dube SK, Chittibabu P, Rao AD, Sinha PC, Murty TS (2000) Extreme Sea levels associated with severe tropical cyclones hitting Orissa coast of India. Mar Geodesy 23(2):75-90

Elsner JB, Kossin JP, Jagger TH (2008) The increasing intensity of the strongest tropical cyclones. Nature 455(7209):92-95

Emanuel K (2005) Increasing destructiveness of tropical cyclones over the past 30 years. Nature 436(7051):686-688

Evan AT, Camargo SJ (2011) A climatology of Arabian Sea cyclonic storms. J Climate 24(1):140-158

Gayathri R, Debabrata Sen (2015) Numerical study on storm surge and associated coastal inundation for 2009 AILA cyclone in the head Bay of Bengal. Aquat. Proc. 4: 404-411

Girishkumar, M. S., and Ravichandran, M. (2012), The influences of ENSO on tropical cyclone activity in the Bay of Bengal during OctoberDecember, J. Geophys. Res., 117(2):1-13 doi:10.1029/2011JCo07417.

Hoeffding W (1957) Rank Correlation Methods by. Journal of The Econometric Society 25:181-183

IMD (2008) Report on cyclonic disturbances over North Indian Ocean during 2007, New Delhi

IMD (2016) Report on cyclonic disturbances over North Indian Ocean during 2015, New Delhi

IMD (2021) Report on cyclonic disturbances over North Indian Ocean during 2021, New Delhi 
801

802

803

804

805

806

807

808

809

810

811

812

813

814

815

816

817

818

819

820

821

822

823

824

825

826

827

828

IPCC (2021) Climate change 2021: The physical science basis. Contribution of working group I to the sixth assessment report of the intergovernmental panel on climate change [Masson-Delmotte, V., P. Zhai, A. Pirani, S.L. Connors, C. Péan, S. Berger, N. Caud, Y. Chen, L. Goldfarb, M.I. Gomis, M. Huang, K. Leitzell, E. Lonnoy, J.B.R. Matthews, T.K. Maycock, T. Waterfield, O. Yelekçi, R. Yu, and B. Zhou (eds.)]. Cambridge University Press. In Press

IPCC (2013) Climate Change 2013: The Physical Science Basis. Contribution of Working Group, I to the Fifth Assessment Report of the Intergovernmental Panel on Climate Change [Stocker, T.F., D. Qin, G.-K. Plattner, M. Tignor, S.K. Allen, J. Boschung, A. Nauels, Y. Xia, V. Bex and P.M. Midgley (eds.)]. Cambridge University Press, Cambridge, United Kingdom and New York, NY, USA, 1535 pp, doi:10.1017/CBO9781107415324

Jeganathan A, Andimuthu R (2013) Developing climate change scenarios for Tamil Nadu. India using MAGICC/SCENGEN. Theor Appl Climatol 114(34):705-714

Knutson T, Camargo SJ, Chan JCL, Emanuel K, Ho CH, Kossin J, Wu L (2019) Tropical cyclones and climate change assessment. Bulletin of the American Meteorological Society 100(10):1987-2007

Knutson TR, Mcbride JL, Chan J, Emanuel K, Holland G, Landsea C, Sugi M (2010) Tropical cyclones and climate change. Nat Geosci 3(3):157- 163

Knutson T R, Sirutis J J, Vecchi G A, Garner S, Zhao M, Kim, H. S., ... Villarini G. (2013) Dynamical downscaling projections of twenty-first century Atlantic hurricane activity: $\mathrm{CMIP}_{3}$ and $\mathrm{CMIP}_{5}$ model-based scenarios. J Climate, 26(17):6591-6617. https://doi.org/10.1175/JCLI-D12-00539.1

Kohno Nadao, Dube Shishir et al (2018) Recent progress in storm surge forecasting. Trop. cyclone res. rev. ESCAP/WMO Typhoon Committee (TC) and Shanghai Typhoon Institute of China Meteorological Administration (STI/CMA), 7(2):128-139

Kossin JP, Olander TL, Knapp KR (2013) Trend analysis with a new global record of tropical cyclone intensity. J Climate, 26(24):9960-9976. https://doi.org/10.1175/JCLI-D-13-00262.1

Kumar S, Lal P, Kumar A (2020) Turbulence of tropical cyclone 'Fani' in the Bay of Bengal and Indian subcontinent. Nat Hazards, 103(1):1613-1622 https://doi.org/10.1007/s11069-020-04033-5

Mann HB (1945) Non-parametric test against trend. Econometrica 13(3):245-259

Mohanty P K, Kar P K, Behera B. (2020) Impact of very severe cyclonic storm Phailin on shoreline change along South Odisha Coast. Nat Hazards, 102(2):633-644. https://doi.org/10.1007/s11069-019-03610-7

Mohapatra M (2015) Cyclone hazard proneness of districts of India. J Earth Syst Sci 124(3):515-526

Mohapatra M, Mandal GS, Bandyopadhyay BK, Tyagi A, Mohanty UC (2012) Classification of cyclone hazard prone districts of India. Nat Hazards 63(3):1601-1620 
Mukhopadhyay P, Taraphdar S, Goswami B N (2011) Influence of moist processes on track and intensity forecast of cyclones over the north Indian Ocean. J Geophys Res 116: Do5116. https:// doi. org/ 10. 1029/ 2010J Do147 00

Muni Krishna K (2009) Intensifying tropical cyclones over the North Indian Ocean during summer monsoon-Global warming. Global and Planetary Change, 65(1-2):12-16. https://doi.org/10.1016/j.gloplacha.2008.10.007

840

Murakami H, Sugi M, Kitoh A (2013) Future changes in tropical cyclone activity in the North Indian Ocean projected by high-resolution MRIAGCMs. Clim Dyn 4O(7-8):1949-1968

843

Murakami H, Vecchi GA, Underwood S (2017) Increasing frequency of extremely severe cyclonic storms over the Arabian Sea. Nature Climate Change 7(12):885-889

846

NDMA (2017) 'National Disaster Management Guidelines: Annual Report'. Published by National Disaster Management Authority, Government of India. 2017, New Delhi

850 Customization of WRF-ARW model with physical parameterization schemes for the simulation of tropical cyclones over North Indian Ocean. Nat Hazards, 63(3):1337-1359. https://doi.org/10.1007/s11069-0119862-0

Raghavan S, Rajesh S (2003) Trends in tropical cyclone impact: A study in Andhra Pradesh. India Bulletin of the American Meteorological Society 84:635-644

Rao A D, Upadhaya P, Ali H, Pandey S, Warrier V (2020) Coastal inundation due to tropical cyclones along the east coast of India: an influence of climate change impact. Nat Hazards, 101(1):39-57. https://doi.org/10.1007/s11069-020-03861-9

Roy Chowdhury R, Prasanna Kumar S, Narvekar J., \& Chakraborty A. (2020) Back-to-Back Occurrence of Tropical Cyclones in the Arabian Sea During October-November 2015: Causes and Responses. J Geophys Rese: Oceans, 125(6). https://doi.org/10.1029/2019JCo15836

RSMC-Tropical Cyclones, New Delhi (1990-2020) Reports on cyclonic disturbances over the north Indian Ocean. No. MOES/IMD/RSMCTropical Cyclone Report. Ministry of Earth Sciences (MoES) Earth System Science Organisation

Sahoo B, Bhaskaran P K (2016) Assessment on historical cyclone tracks in the Bay of Bengal, east coast of India. Int J Climatol, 36(1): 95-109. https://doi.org/10.1002/joc.4331

Sahoo B, Bhaskaran P K (2018) Multi-hazard risk assessment of coastal vulnerability from tropical cyclones - A GIS based approach for the Odisha coast. Journal of Environmental Management, 206:1166-1178. https://doi.org/10.1016/j.jenvman.2017.10.075

Sattar AM, Cheung KKW (2019) Comparison between the active tropical cyclone seasons over the Arabian Sea and Bay of Bengal. Int J Climatol 39(14):5486-5502

880

881

882

883

884

885

886 
Singh K, Panda J et al (2016) Progress in tropical cyclone predictability and present status in the north Indian ocean region. In: Recent developments in tropical cyclone dynamics, prediction, and detection. https://doi.org/10.5772/ 64333

Singh OP, Khan TMA, Rahman MS (2001) Has the frequency of intense tropical cyclones increased in the North Indian Ocean? Curr Sci 80:575580

Singh OP, Ali Khan TM, Rahman MS (2000) Changes in the frequency of tropical cyclones over the North Indian Ocean. Meteorology and Atmospheric Physics 75(1-2):11-20. https://doi.org/10.1007/s007030070011

Singh VK, Roxy MK, Deshpande M (2020) The unusual long track and rapid intensification of very severe cyclone Ockhi. Curr Sci 119:771-779

Soltanpour M, Ranji Z, Shibayama T, Ghader S (2021) Tropical Cyclones in the Arabian Sea: overview and simulation of winds and storm-induced waves. Nat Hazards, 108(1):711-732. https://doi.org/10.1007/s11069021-04702-Z

Vieira F, Cavalcante G, Campos E (2021) Simulation of cyclonic wave conditions in the Gulf of Oman. Nat Hazards, 105(2):2203-2217. https://doi.org/10.1007/s11069-020-04396-9

Wahiduzzaman M, Yeasmin A (2019) Statistical forecasting of tropical cyclone landfall activities over the north Indian ocean rim countries. Atmospheric Research 227: 89-100

Walsh, K. J. E., Mcbride, J. L., Klotzbach, P. J., Balachandran, S., Camargo, S. J., Holland, G., ... Sugi, M. (2016) Tropical cyclones and climate change. Wiley Interdisciplinary Reviews: Climate Change, 7(1):65-89. https://doi.org/10.1002/wcc.371

Webster PJ, Holland GJ, Curry JA, Chang HR (2005) Atmospheric science: Changes in tropical cyclone number, duration, and intensity in a warming environment. Science 309:1844-1846

Zhang W, Villarini G (2019) On the role of the Atlantic Ocean in forcing tropic cyclones in the Arabian Sea. Atmospheric Research 220:120-124

Zhou Y, Matyas C, Li H, Tang J (2018) Conditions associated with rain field size for tropical cyclones landfalling over the Eastern United States. Atmospheric Research 214:375-385 


\section{List of Figures}

1 Time series of cyclone frequency in AS from 1982 to 2020 along with the trendline which shows an increasing trend in the frequency of TC over the period

2 a) Depiction of annual frequency, frequency of CS, SCS, VSCS, ESCS and SuCS in two epochs i.e., 1982-200o, the bygone era (BE) and 2001-2020, the current era (CE). The five coloured bar represents five different categories of TCs. The alarming increase in the frequency of TCs is echoed in CE. b) Representation of seasonal frequency of TCs in AS in four panels OND (post-monsoon, JJAS (monsoon), MAM (premonsoon) and JF (January-February). The figure shows that the increase in the annual frequency of cyclones is due to the increase in post-monsoon TCs

24

3 Comparison of frequency of TCs formed over BoB and AS during the period 1982 to 2020. The blue dots in each panel represents the frequency of TCs in BoB and the yellow dots represents the frequency of TCs in AS. a) Representation of decreasing frequency in the frequency of CS in AS and BoB. b) Decrease in the frequency of SCS in both basins. c) Decrease in BoB frequency and increase in AS frequency for VSCS. d) Depicts an increasing trend in $\mathrm{AS}$ and no trend in BoB for ESCS. e) Represents there is no increase or decrease in the frequency of $\mathrm{BoB}$ and $\mathrm{AS}$ for SuCS.

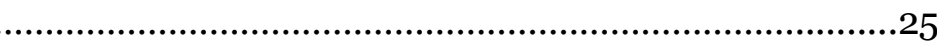

4 a) Representation of ACE and PDI from 1982-2020. The area under the graph for both ACE and PDI shows an increase in the energy metrics over the time period indicating the increase in devastation potential of TCs over the period. b) Depiction of BE annual ACE, pre-monsoon ACE, post-monsoon ACE and monsoon ACE with trendlines. c) Depiction of CE annual ACE, pre-monsoon ACE, post-monsoon ACE and monsoon ACE with trend lines. The figure clearly shows that the ACE values for all seasons and annual values increase many folds in CE compared to $\mathrm{BE}$. Even within $\mathrm{CE}$, the values are extremely high after $2014 \ldots . .26$

5 Illustration of monsoon ACE and PDI in BE and CE. 5a) Represent BE ACE with an increasing trend. 5b) Shows CE ACE with a steep slope indicating the increasing trend. 5c) Represent BE PDI with a slightly increasing trend. 5d) Shows CE PDI with a steep increasing trend. 
6 Representation Nino 3.4 index and frequency of TC. Panel 1 shows Nino 3.4 index and panel 2 shows ACE, PDI and frequency of TCs from 1982 to 2020. No pattern is observed TC parameters connecting to the Nino3.4

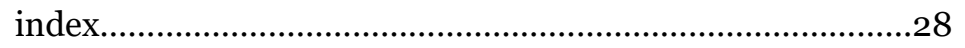

7 a) Vulnerability of districts on the west coast of India based on roof types. Districts marked red are highly vulnerable, yellow is moderately vulnerable, and green depicts low vulnerability. b) Vulnerability of districts on the west coast of India based on the wall type. Districts marked red are highly vulnerable, yellow is moderately vulnerable and green shows low vulnerability...... 
989

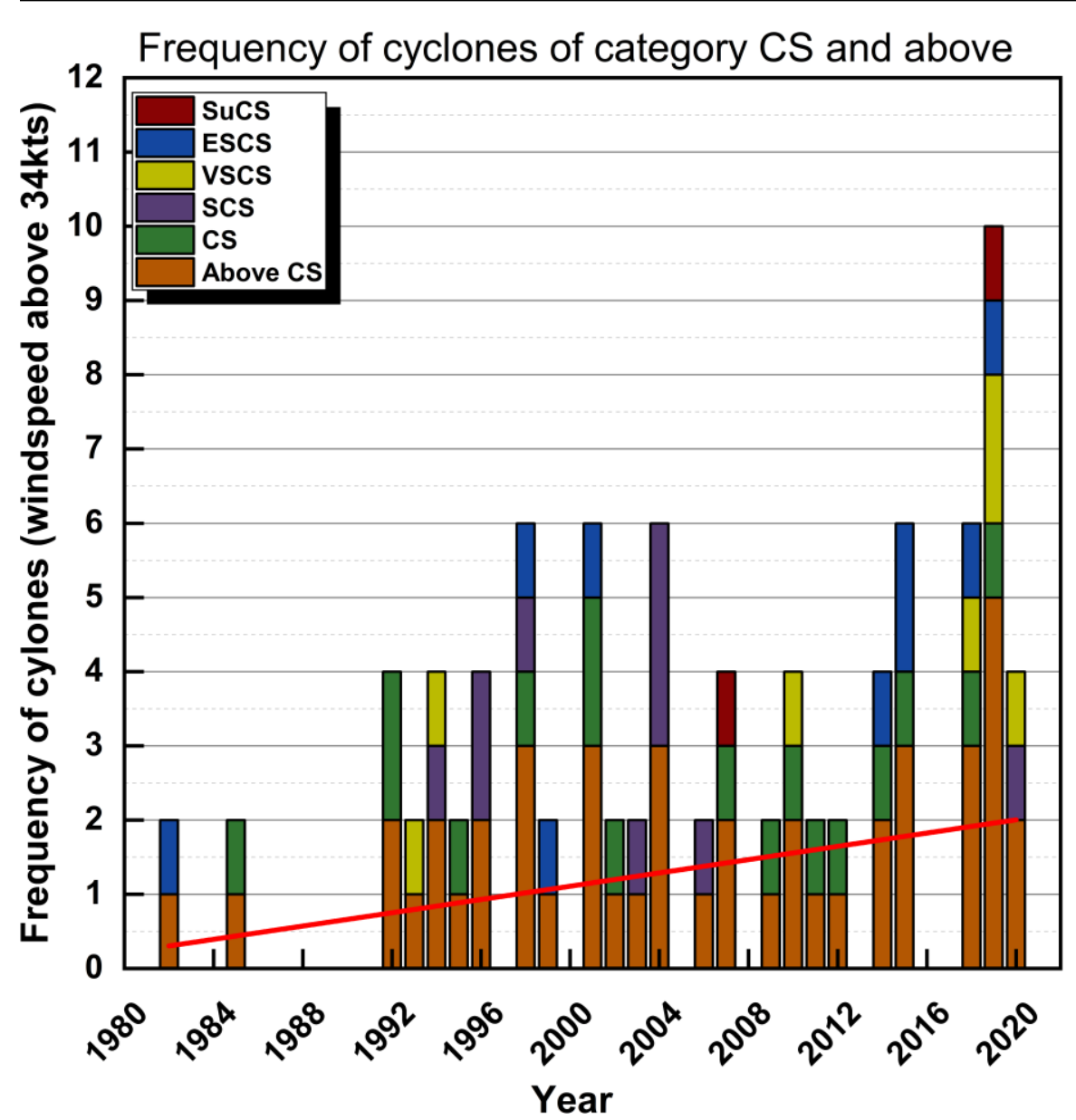

Fig. 1 Time series of cyclone frequency in AS from 1982 to 2020 along with the trendline 
995
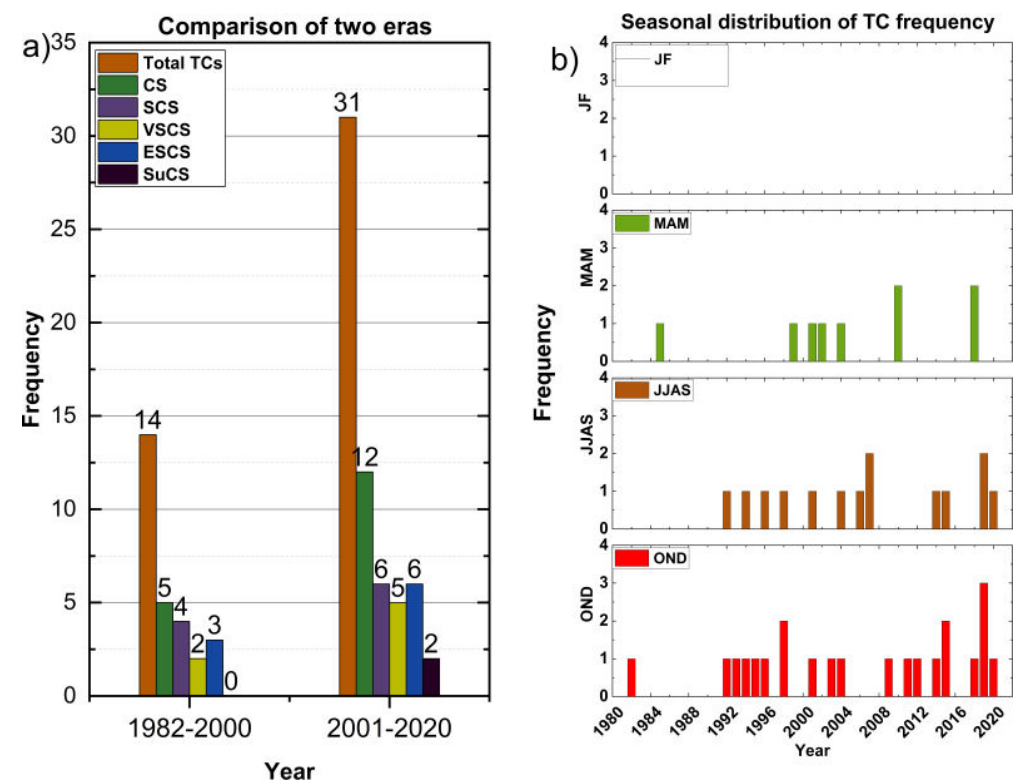

Fig. 2 a) Depiction of annual frequency, frequency of CS, SCS, VSCS, ESCS and SuCS in two epochs i.e., 1982-2000, the bygone era (BE) and 2001-2020, the current era (CE). The coloured bar represents five different categories of TCs. The alarming increase in the frequency of TCs is echoed in CE. b) Representation of seasonal frequency of TCs in AS in four panels OND (post-monsoon, JJAS (monsoon), MAM (pre-monsoon) and JF (January-February). The figure shows that the increase in the annual frequency of cyclones is due to the increase in post-monsoon TCs. 
1005
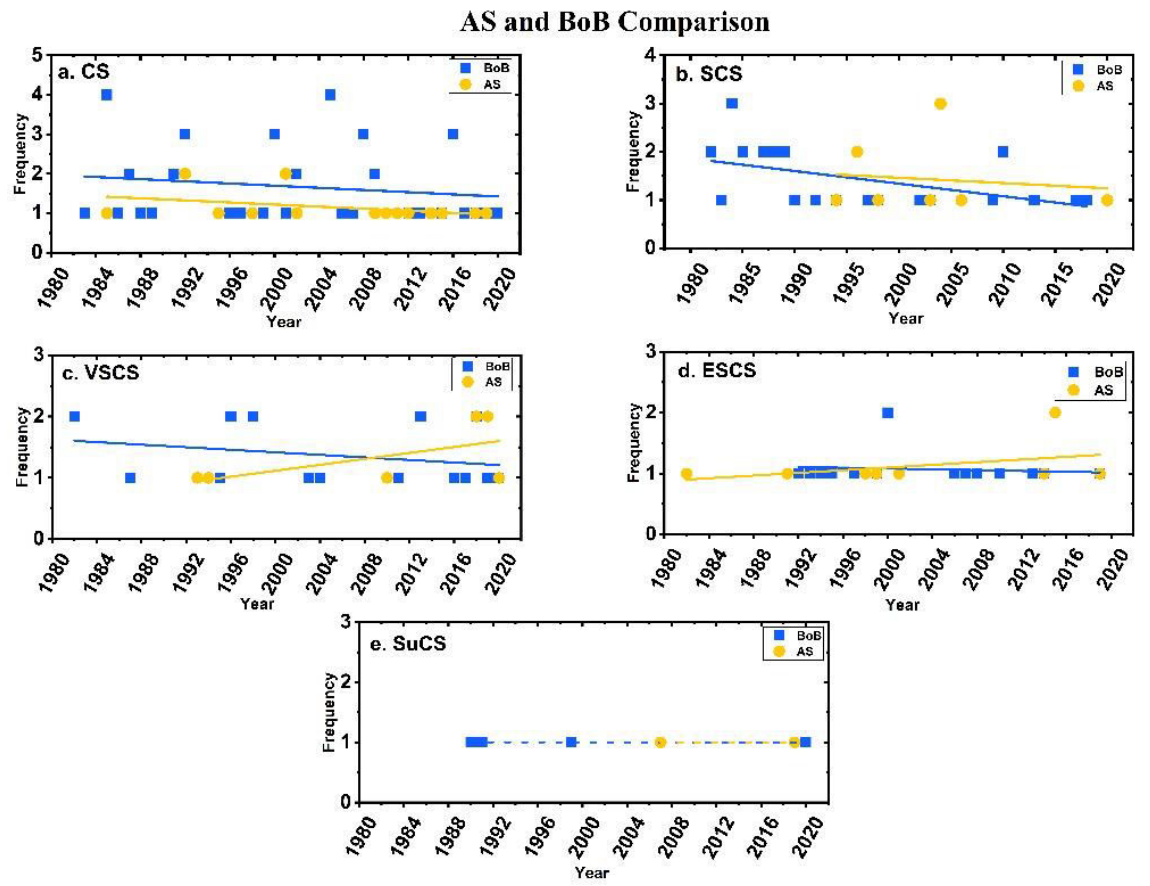

1006

1007

1008

1009

1010

1011

1012

1013

Fig. 3 Comparison of frequency of TCs formed over BoB and AS during the period 1982 to 2020. The blue dots in each panel represents the frequency of TCs in BoB and the yellow dots represents the frequency of TCs in AS. a) Representation of decreasing frequency in the frequency of CS in AS and BoB. b) Decrease in the frequency of SCS in both basins. c) Decrease in BoB frequency and increase in AS frequency for VSCS. d) Depicts an increasing trend in AS and no trend in BoB for ESCS. e) Represents there is no increase or decrease in the frequency of BoB and AS for SuCS. 

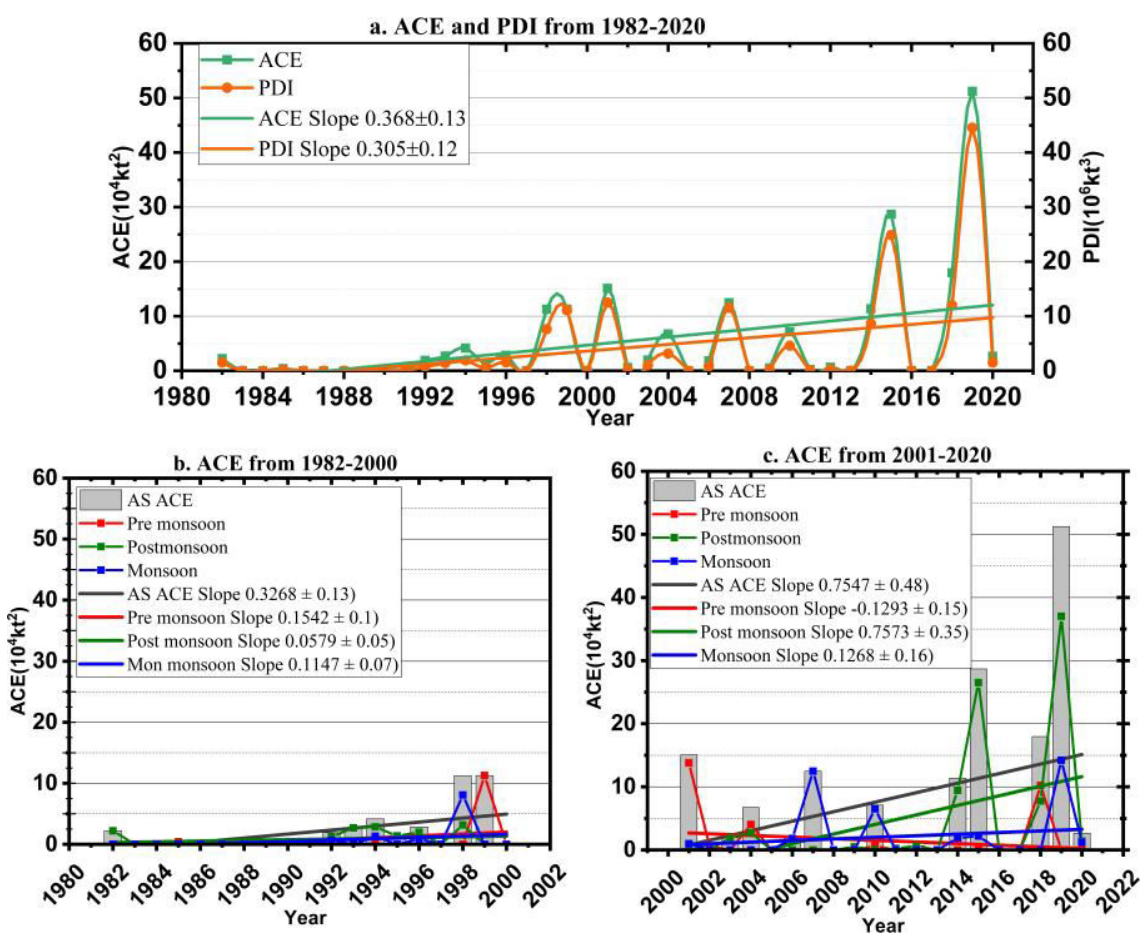

Fig. 4 a) Representation of ACE and PDI from 1982-2020. The area under the graph for both ACE and PDI shows an increase in the energy metrics over the time period indicating the increase in devastation potential of TCs over the period. b) Depiction of BE annual ACE, pre-monsoon ACE, post-monsoon ACE and monsoon ACE with trendlines. c) Depiction of $\mathrm{CE}$ annual ACE, pre-monsoon ACE, post-monsoon ACE and monsoon ACE with trend lines. The figure clearly shows that the ACE values for all seasons and annual values increase many folds in CE compared to BE. Even within CE, the values are extremely high after 2014. 

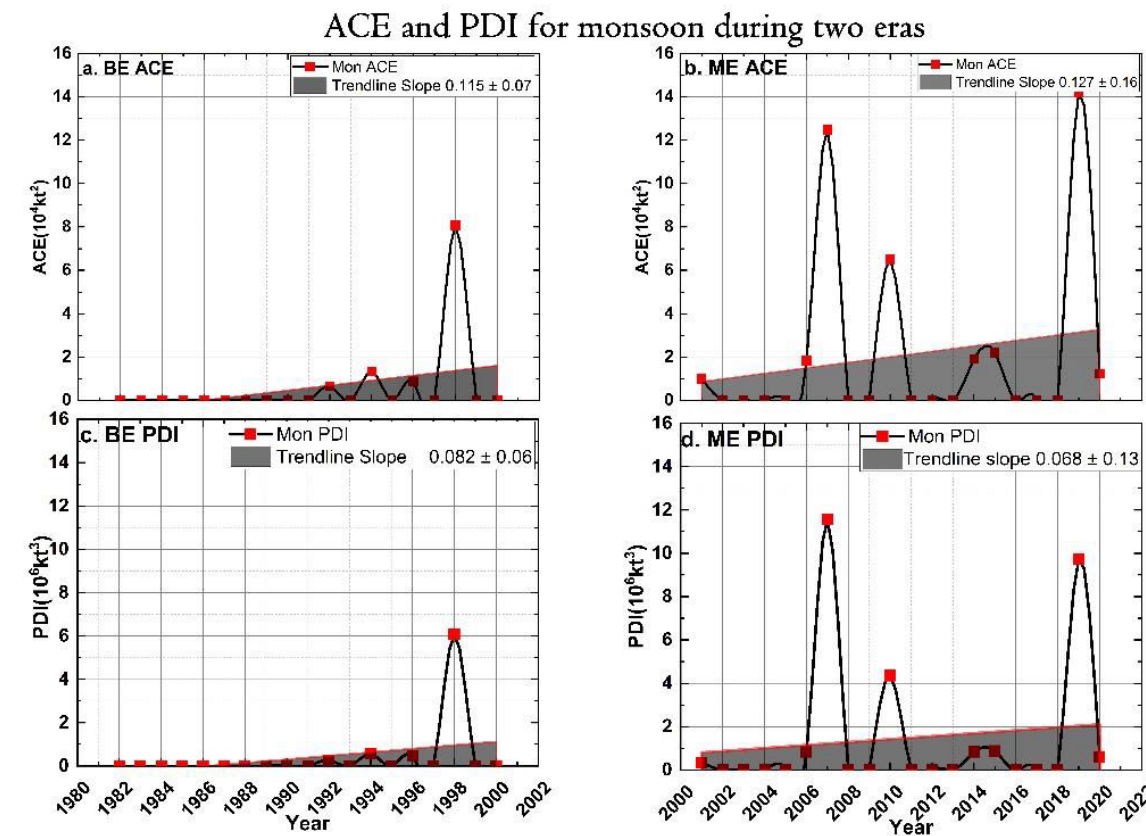

Fig. 5 Illustration of monsoon ACE and PDI in BE and CE. 5a) Represent BE ACE with an increasing trend. 5b) Shows CE ACE with a steep slope indicating the increasing trend. 5c) Represent BE PDI with a slightly increasing trend. 5d) Shows CE PDI with a steep increasing trend. 
1031
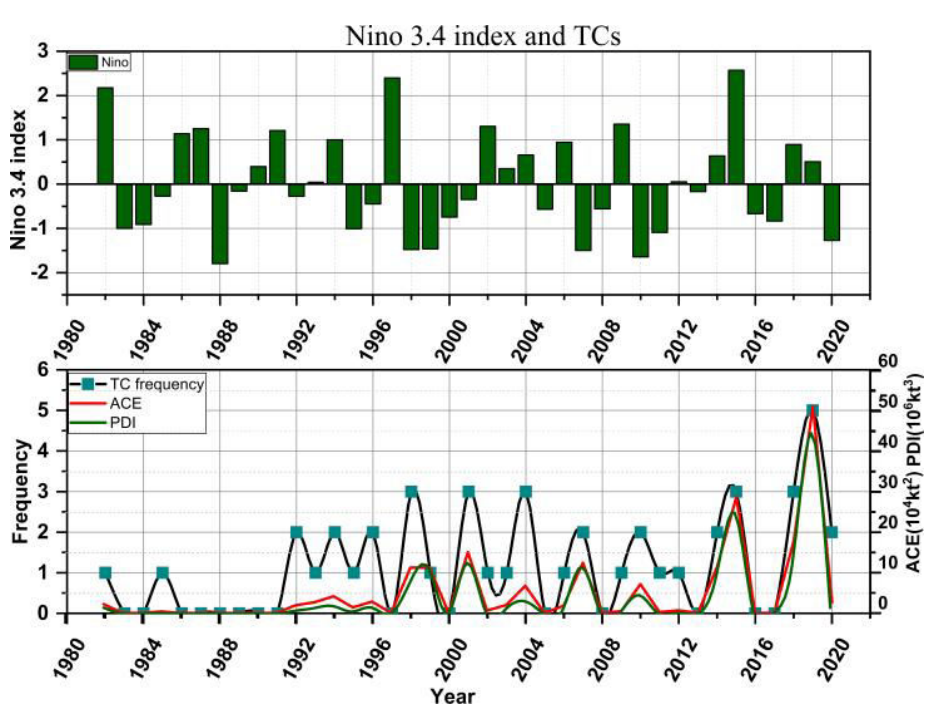

1033

1034

1035

1036

1037

Fig. 6 Representation Nino 3.4 index and frequency of TC. Panel 1 shows Nino 3.4 index and panel 2 shows ACE, PDI and frequency of TCs from 1982 to 2020 . No pattern is observed TC parameters connecting to the Nino3.4 index. 
1038

1039

1040

1041

1042

1043

1044

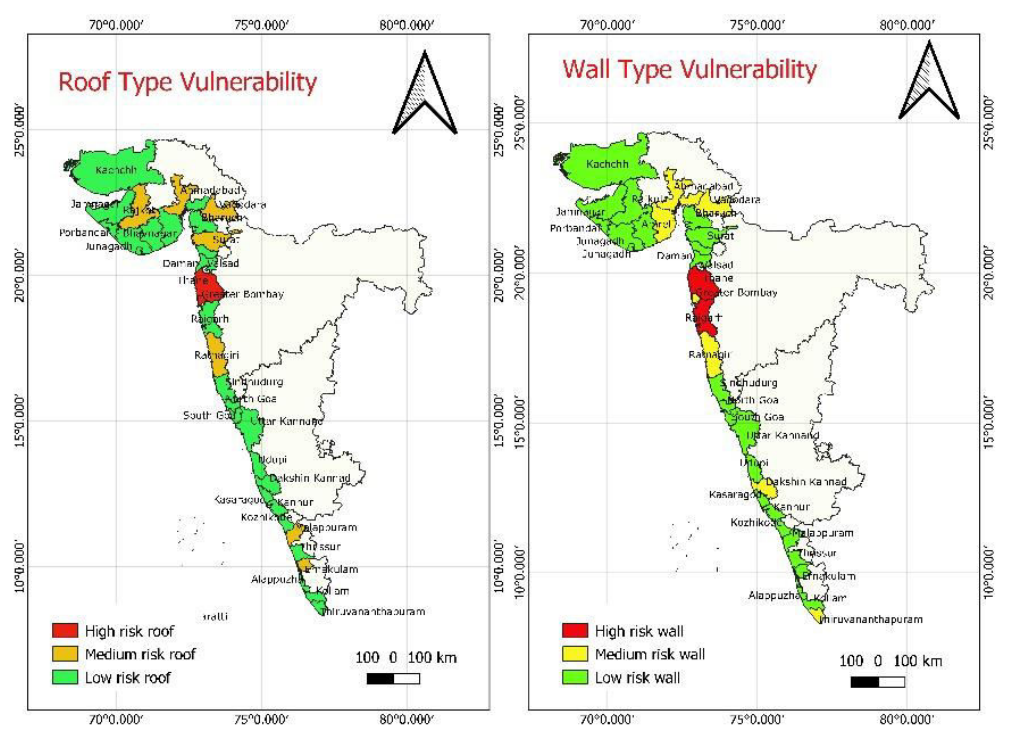

Fig. 7 a) Vulnerability of districts in the west coast of India based on roof types. Districts marked red are highly vulnerable, yellow are moderately vulnerable, and green depicts low vulnerability. b) Vulnerability of districts on the west coast of India based on the wall type. Districts marked red are highly vulnerable, yellow are moderately vulnerable and green show low vulnerability. 


\section{List of Tables}

1 Level of risk for different roof types and wall types as calculated and classified in the study ..31

2 MK test results for frequency of TCs over the Arabian sea from 1982-2020. There is a significant positive trend in the frequency of total TCs and the frequency of ESCS. 32

3 Basic statistics of ACE and PDI over the AS from 1982-2020. The table gives the basic statistics of total ACE and PDI, premonsoon, post-monsoon and monsoon values of $\mathrm{ACE}$ and PDI.......33

4 Results of MK test performed for annual and seasonal values of ACE and PDI. A significant positive trend is observed both in annual values of ACE and PDI. The same can be observed in monsoon values of both ACE and PDI.... 
1061

1062

1063

1064

Table 1 Level of risk for different roof types and wall types as calculated and classified in the study

$\begin{array}{cccc}\begin{array}{l}\text { Roof type } \\ \text { vulnerability } \\ \text { index values }\end{array} & \begin{array}{c}\text { Level of } \\ \text { risk } \\ 0-3\end{array} & \begin{array}{c}\text { Wall type } \\ \text { vulnerability } \\ \text { index values }\end{array} & \begin{array}{c}\text { Level of } \\ \text { risk }\end{array} \\ 3-6 & \text { Medium } & 0-10 & \text { Low } \\ 6 \text { and above } & \text { High } & 21-30 & \text { Medium } \\ \end{array}$


Table 2 MK test results for frequency of TCs over the Arabian sea from 1982-2020. There is a significant positive trend in the frequency of total TCs and the frequency of ESCS.

\begin{tabular}{llll}
\hline Frequency & $\begin{array}{c}\text { MK } \\
\text { p-value }\end{array}$ & $\begin{array}{c}\text { z- } \\
\text { value }\end{array}$ & \multicolumn{1}{|l}{ Inference } \\
Total TC & 0.016 & 2.400 & Significant positive trend \\
CS & 0.07 & 1.8072 & No monotonic trend \\
SCS & 0.635 & 0.4735 & No monotonic trend \\
VSCS & 0.057 & 1.9031 & No monotonic trend \\
ESCS & 0.035 & 2.0987 & Significant positive trend \\
SuCS & 0.134 & 1.4963 & No monotonic trend
\end{tabular}

$\begin{array}{llll}\text { SuCS } & 0.134 & 1.4963 \text { No monotonic trend }\end{array}$ 
Table 3 Basic statistics of ACE and PDI over the AS from 1982-2020. The table gives the basic statistics of total ACE and PDI, pre-monsoon, post-monsoon and monsoon values of $\operatorname{ACE}\left(10^{4} k t^{2}\right)$ and PDI $\left(10^{6} k t^{3}\right)$.

1153

1154

1155

Total

Pre-monsoon Post- monsoon

Monsoon

1156

1157

\begin{tabular}{lllllllll} 
& ACE & PDI & ACE & PDI & ACE & PDI & ACE & PDI \\
Minimum & 0 & 0 & 0 & 0 & 0 & 0 & 0 & 0 \\
Maximum & 51.22 & 44.56 & 13.78 & 12.05 & 37.02 & 34.83 & 14.20 & 11.55 \\
Range & 51.22 & 44.56 & 13.78 & 12.05 & 37.02 & 34.83 & 14.20 & 11.55 \\
Median & 0.650 & 0.23 & 0 & 0 & 0 & 0 & 0 & 0 \\
Mean & 5.06 & 3.91 & 1.05 & 0.85 & 2.67 & 2.12 & 1.338 & 0.93 \\
SE.mean & 1.58 & 1.36 & 0.52 & 0.45 & 1.16 & 1.07 & 0.527 & 0.41 \\
CI.mean.0.95 & 3.19 & 2.75 & 1.05 & 0.91 & 2.35 & 2.17 & 1.067 & 0.84 \\
Variance & 97.18 & 72.25 & 10.42 & 7.85 & 52.53 & 44.98 & 10.84 & 6.65 \\
Standard Deviation & 9.86 & 8.5 & 3.23 & 2.80 & 7.25 & 6.71 & 3.29 & 2.58 \\
Coefficient of variance & 1.95 & 2.18 & 3.07 & 3.31 & 2.71 & 3.15 & 2.46 & 2.76 \\
\hline
\end{tabular}

1158

1159

1160 
1161 Table 4 Results of MK test performed for annual and seasonal values of ACE and PDI. A 1162 significant positive trend is observed both in annual values of ACE and PDI. The same can 1163 be observed in monsoon values of both ACE and PDI.

\begin{tabular}{lclll}
\hline Parameter & $\begin{array}{c}\text { MK } \\
\mathbf{Z} \text { value }\end{array}$ & P-value & $\begin{array}{c}\text { Sen's } \\
\text { Slope }\end{array}$ & Inference \\
& & & & \\
ACE & 2.407 & 0.016 & 0.044 & Significant positive trend \\
Pre monsoon & 0.472 & 0.637 & 0 & No significant trend \\
Post monsoon & 1.875 & 0.061 & 0 & No significant trend \\
Monsoon & 2.154 & 0.031 & 0 & Significant positive trend \\
PDI & 2.358 & 0.018 & 0.016 & Significant positive trend \\
Pre monsoon & 0.472 & 0.637 & 0 & No significant trend \\
Post monsoon & 1.743 & 0.081 & 0 & No significant trend \\
Monsoon & 2.124 & 0.034 & 0 & Significant positive trend \\
\hline
\end{tabular}

1165 


\section{Supplementary Files}

This is a list of supplementary files associated with this preprint. Click to download.

- SupplementaryInformation.docx 